\title{
Laboratory Study on CR/SBS Modified Asphalt: Preparation and Performance Characterization
}

\author{
Liang Song ${ }^{1,2,3}$, Guoqiang Zhang ${ }^{2}$, Hongfei $\mathrm{Xie}^{2}$ and Jie Gao ${ }^{4, *}$ \\ ${ }^{1}$ College of Transportation Engineering, Tongji University, Shanghai, 201804, China \\ ${ }^{2}$ Xinjiang Transportation Planning Surveying and Design Institute, Urumqi, 830006, China \\ ${ }^{3}$ Xinjiang NABA Expressway Development Co., Ltd., Urumqi, 830006, China \\ ${ }^{4}$ School of Civil Engineering and Architecture, East China Jiaotong University, Nanchang, 330013, China \\ *Corresponding Author: Jie Gao. Email: gaojie@ecjtu.edu.cn
}

Received: 16 July 2021 Accepted: 18 September 2021

\begin{abstract}
Crumble rubber (CR) can be used to prepare CR and styrene-butadiene-styrene (SBS) composite modified asphalt with a good high-and low-temperature performance, meanwhile the addition of CR could work as the substitute for SBS and help reduce the content of SBS. This study contains three main parts: effect of preparation and effect of material composition as well as rheological performance characterization. Factors during the preparation, including shearing temperature, shearing time, mixing time and swelling time, were selected, while base binder, CR content, CR particle size and SBS content in material composition were considered. The effects of these factors were assessed in terms of the conventional performance (penetration, softening point, ductility and storage stability). After identifying these effects, the sample of CR and SBS modified asphalt at the selected preparing condition and material composition (CR/SBSMA) was made, and the corresponding SBS modified and CR modified asphalt (SBSMA and CRMA) were produced for the comparing reason. Subsequently, temperature sweeps from $0^{\circ} \mathrm{C}$ to $80^{\circ} \mathrm{C}$ were utilized to depict the viscoelasticity of these modified asphalt binders by complex modulus and phase angle. Multiple stress creep recovery tests (MSCR) at $64^{\circ} \mathrm{C}$ and bending beam rheometer tests (BBR) at various low temperatures were employed to evaluate the high-and low-temperature performance, respectively. Results highlight that that CR/SBSMA could exhibit an excellent high-temperature performance (better than SBSMA), and a good low-temperature performance (reaching the level of base binder).
\end{abstract}

\section{KEYWORDS}

Crumble rubber; styrene-butadiene-styrene; preparation; material composition; high-temperature performance; low-temperature performance

\section{Introduction}

Rheological properties of asphalt binders play an important role in determining the pavement performance and the distresses caused by traffic loading and natural environment [1]. So, highperformance pavement materials have been pursued for a long period, among which the addition of polymers into asphalt binders could be one of the most frequently used method [2]. A number of studies and projects attempted to make a good application of types of polymers, meanwhile researchers evaluated 
and tried to maximize the benefits of use of polymers, from various aspects (e.g., high-temperature antirutting, low-temperature anti-cracking, storage stability and aging performances) [3-7]. Among polymers, styrene-butadiene-styrene (SBS) modified asphalt could be the preferred one, mainly due to its overwhelmingly good high-temperature anti-rutting and anti-fatigue performance as well as high strength [8-10].

The great improvement in performance of SBS modified asphalt mainly comes from the molecular structure of SBS, which is copolymerized by glassy polystyrene (PS) and rubbery polybutadiene (PB) chains. Glass transition temperature (Tg) of PS locates at about $95^{\circ} \mathrm{C}$, while $\mathrm{Tg}$ of $\mathrm{PB}$ reaches to as low as $-80^{\circ} \mathrm{C}$ [11]. The surrounding temperature of pavements at the service period could be fully within the range of $-80^{\circ} \mathrm{C}$ and $95^{\circ} \mathrm{C}$ (between $\mathrm{Tg}$ of $\mathrm{PB}$ and $\mathrm{Tg}$ of PS). So, the relatively high strength and hardness of SBS is endowed by glassy PS segments, while elasticity of SBS is greatly improved by the elastic PB segments [12]. Further, after mixing and shearing with asphalt binder at high temperature, SBS tends to absorb maltene (light components) and swell $[3,13]$. Meanwhile, these swollen SBS particles could contact with each other to form three dimensional networks, when the amount of SBS added in asphalt binders is enough [14]. These evenly-dispersed SBS particles in asphalt binders greatly enhance stiffness and viscosity of the system composed by SBS and base binders [15]. The elasticity at high temperature could be effectively maintained due to the formation of 3D SBS networks, which can be proved by phase angle vs. temperature curves, where phase angle remains stable and inconspicuously go up with the increasing temperature [16]. Recently, high content SBS polymers modified asphalt was developed to pursuit the high strength and viscosity to meet the requirement set by a functional asphalt mixture (OpenGraded Friction Course) for permeable pavement [17]. But, the usage of SBS modified asphalt is often limited to expressways and other high-level highways in China, due to its high construction costs.

As compared with SBS, Crumb Rubber (CR) obtained from waste tires has a superior advantage: cost (about $300 \$$ ton versus around $1400 \$ /$ ton, in China) [18]. Additionally, it was reported that more than one billion tires are produced every year [19]. These waste tires are often disposed as land-fill without proper processing, which has a great possibility of causing environmental problems due to the accumulation of hazardous materials [20]. So, incorporating CR into paving materials could be a promising technology, from the perspectives of both economy and environment. In fact, it has been a long history (more 50 years) since researchers attempted to employ $\mathrm{CR}$ as an elastic asphalt binder addictive [21,22]. Nowadays, there are mainly three ways to incorporating CR into asphalt mixtures: dry process and wet process as well as terminal blend rubberized asphalt (TBRA). In the method of dry process, CR, as a substitute for fine aggregates, is directly mixed with aggregates and asphalt binders [23]. Normally, the hot asphalt mixtures contain CR produced by the dry process will be constructed immediately, otherwise it will face the serious segregation problem. The wet process is carried out by blending CR and base binders by high-speed shear mixer at high temperature for a long time to ensure enough physical and chemical interactions between $\mathrm{CR}$ and base binders [24]. TRBA method was developed to aim to alleviate storage stability problems, employing as high as the temperature of $200^{\circ} \mathrm{C}$ to $260^{\circ} \mathrm{C}$ to depolymerize CR molecules, so that the molecular chains would be cut into the shorter [25]. This would facilitate swelling and dissolving of CR particles in asphalt binders and effectively reduce the segregation problems. Yet, a side effect from TRBA is that degradation and depolymerization of CR molecules at very high temperature during processing would exert an adverse effect on high-temperature rutting performance.

To reach strength and high-temperature performance as good as SBS modified asphalt, extreme high content of CR (e.g., 20\%) may need to be added, but it may accelerate segregation between CR and base binders and lead to serious storage stability issues [26]. So, attempts to combine CR and low-content SBS without compromising performance have attracted high interests among researchers. Numerous studies confirmed the great possibility of CR and SBS modified asphalt, since the elastic response and 
resistance to permanent deformation at high temperature were significantly improved [26-28]. Resistance to cracking at low temperature domains could be also obviously enhanced due to the high elasticity and softening effect from CR particles. It was proved that rubble molecules could also participate in the crosslinking among polymers, which strengthen the 3D polymers networks and improve viscoelasticity towards a better road performance at large temperature domain [3,26,29]. Additionally, swelling and degradation levels have been found to lead an important role in physical and rheological properties of CR and SBS composite modified asphalt [30-32]. Higher swelling level of CR contributed to higher viscosity, while the increasing degradation on CR could have an adverse effect on the viscosity of CR and SBS composite modified asphalt.

Though a number of researches on CR and SBS modified asphalt have been carried out, the variety of chemical compositions in asphalt binder could lead to the great uncertainty in the performance of the CR and SBS modified asphalt, and also, the optimum preparation process and material composition also could vary. In this study, two local-produced base binders (KL and $\mathrm{TH}$ ) would be used to prepare CR and SBS modified asphalt. Then, a series of factors at preparation process and material composition were considered to find out their effect on the conventional performance of CR and SBS modified asphalt. Last, CR and SBS modified asphalt binder at the selected conditions were produced and evaluated in terms of rheological performance. The specific objective of this work is to

(1) Investigate the effect of preparation process on the conventional performance,

(2) Characterize the effect of material composition on the conventional performance and

(3) Evaluate the rheological performance of CR/SBS composite modified asphalt.

\section{Materials and Experiments}

\subsection{Raw Materials}

Two base binders of KL-90\# asphalt, produced by PetroChina company in Karamay, Xinjiang Province, China, and TH-60\# asphalt, produced by Petrochemical company, in Tarim, Xinjiang Province, China, were blended to prepare the modified asphalt samples. The usage of two base binders produced in Xinjiang Province is required by the research project. The basic properties for two base binders are shown in Table 1 .

Table 1: The information of basic properties

\begin{tabular}{llll}
\hline Items & KL-90\# & TH-60\# & Test methods \\
\hline Penetration at $25^{\circ} \mathrm{C}(0.1 \mathrm{~mm})$ & 91.1 & 64.3 & ASTM D5 \\
Softening point $\left({ }^{\circ} \mathrm{C}\right)$ & 46.5 & 57.8 & ASTM D36 \\
Ductility at $15^{\circ} \mathrm{C}(\mathrm{cm})$ & $>100$ & $>100$ & ASTM D113 \\
Mass loss after RTFO $(\%)$ & 0.08 & 0.05 & ASTM D2872 \\
Penetration at $25^{\circ} \mathrm{C}$ after RTFO $(0.1 \mathrm{~mm})$ & 62.6 & 42 & ASTM D5 \\
Softening point after RTFO $\left({ }^{\circ} \mathrm{C}\right)$ & 57.6 & 62.5 & ASTM D36 \\
Ductility at $15^{\circ} \mathrm{C}$ after RTFO $(\mathrm{cm})$ & 26.7 & 40.1 & ASTM D113 \\
\hline
\end{tabular}

Note: RTFO corresponds to the standard short-term aging (Rolling Thin Film Oven, RTFO).

The main finding reported from the elemental analysis (Fig. 1) is that the aromatic carbon ratio of TH (0.771) is obviously higher than it of KL (0.738), meanwhile the aromatic carbon mainly exists in the fractions of aromatic and asphaltene. This may reveal that there are higher content of aromatic and asphaltene in TH than KL. 

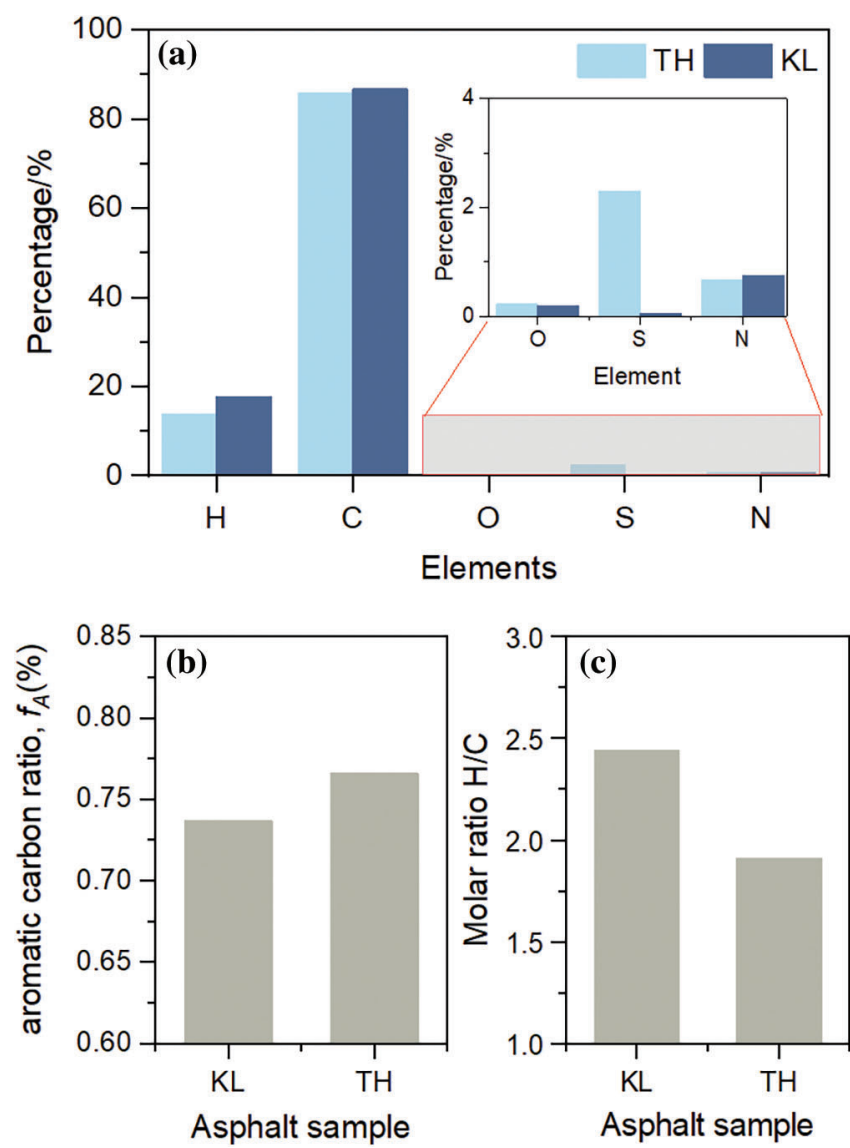

Figure 1: Elemental analysis results of two asphalt binders obtained by vario MACRO cube organic element analyzer. a): element contents, b): aromatic carbon ratio and c): molar ratio of $\mathrm{H} / \mathrm{C}$

From the 2D and 3D surface topography images of TH and KL (Fig. 2), the main difference of two asphalt binders is the bee structure. There are a number of bee structures in TH, while there are few bee structures in KL. Recent researches proved that the origin of bee structures has a close relationship with asphaltene and wax [33]. So, this AFM images may reveal that there are fewer asphaltene in KL than it in $\mathrm{TH}$.
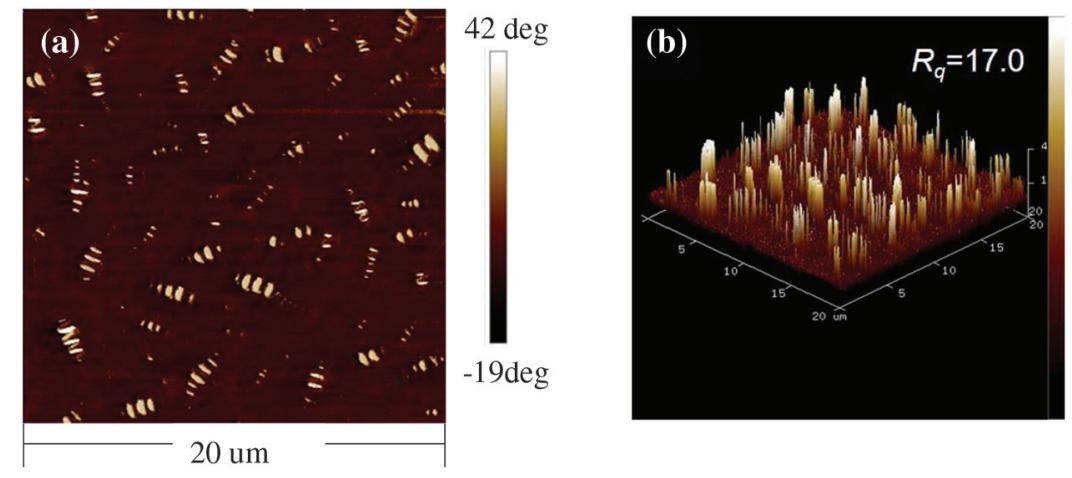

Figure 2: (Continued) 

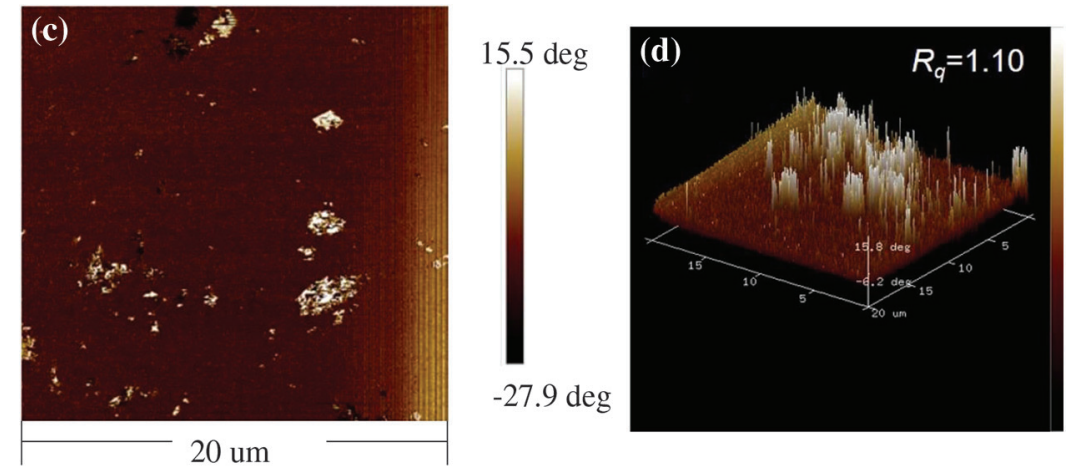

Figure 2: The surface topography of two investigated asphalt binders obtained by PICO PLUS atomic force microscope (AFM), (a), (b) is 2D and 3D AFM images of TH; (c), (d) is 2D and 3D AFM images of KL

The SBS polymer (Dushanzi T6302) was produced by Petrochemical company in Karamay, Xinjiang Province, China. The fundamental information of this SBS polymer is presented in Table 2. Crumb rubber (CR) used in this study was purchased from Baoli International Investment Co., Ltd., Jiangsu Province, China, and the CR was produced from waste tires with the employment of freezing comminution technology. Before added into the asphalt binders, the CR was sieved to the required mesh. The technical parameters are listed in Table 3.

Table 2: The information of basic properties for SBS polymer

\begin{tabular}{lll}
\hline Items & Units & SBS \\
\hline Molecular structure & - & Linear \\
Styrene-butadiene ratio & - & $30 / 70$ \\
Average molecular weight & $10^{4} \mathrm{~g} \cdot \mathrm{mol}^{-1}$ & 10.0 \\
Volatility & $\%$ & 0.7 \\
Ash content & $\%$ & 0.2 \\
Tensile strength & $\mathrm{MPa}$ & 20 \\
Breaking elongation & $\%$ & 700 \\
Shore hardness & $\mathrm{A}$ & 77 \\
Melt flow rate & $\mathrm{g} \cdot \mathrm{min}^{-1}$ & $0.1-5$ \\
\hline
\end{tabular}

Table 3: The information of basic properties for CR

\begin{tabular}{lllllllll}
\hline Items & Density & $\begin{array}{l}\text { Water } \\
\text { content }\end{array}$ & $\begin{array}{l}\text { Metal } \\
\text { content }\end{array}$ & $\begin{array}{l}\text { Fiber } \\
\text { content }\end{array}$ & $\begin{array}{l}\text { Ash } \\
\text { content }\end{array}$ & $\begin{array}{l}\text { Mass loss } \\
\text { after heating }\end{array}$ & $\begin{array}{l}\text { Carbon black } \\
\text { content }\end{array}$ & $\begin{array}{l}\text { Rubber } \\
\text { hydrocarbon }\end{array}$ \\
\hline Values & 322.6 & 0.4 & 0.015 & 0.041 & 6.5 & 0.62 & 32 & 51 \\
\hline
\end{tabular}

\subsection{Sample Preparation}

In this work, CR and SBS modified asphalt binders at various preparing conditions and material composition were made, but the main preparation procedure for all CR and SBS modified asphalt binders is as follows: first, two base binder, $\mathrm{KL}$ and $\mathrm{TH}$, at certain ratio, were blended at $135^{\circ} \mathrm{C}$ for about $20 \mathrm{~min}$ 
to reach homogenous using the low-speed mixer $(500 \mathrm{rpm})$; then, the certain amount of CR and SBB were added into the blended asphalt to be sheared by high-speed shearer $(4000 \mathrm{rpm})$ for a period time (shearing time, from 0.5 to $2 \mathrm{~h}$ ) at high temperature (shearing temperature, from $170^{\circ} \mathrm{C}$ to $200^{\circ} \mathrm{C}$ ); after that, the sheared residue, containing $\mathrm{CR}$, SBS and blended asphalt, was removed to the oven at $180^{\circ} \mathrm{C}$ to condition for some time (swelling time, from 0.5 to $2 \mathrm{~h}$ ), which facilitates depolymerization of CR and crosslinking among polymers; Last, the residue after conditioning was mixed to ensure the homogeneity at $180^{\circ} \mathrm{C}$ for some time (mixing time, from 1 to $2.5 \mathrm{~h}$ ).

The standard values of these variables (factors during preparation) are: $180^{\circ} \mathrm{C}$ for the shearing temperature, $1 \mathrm{~h}$ for the shearing time, $1 \mathrm{~h}$ for the swelling time and $1.5 \mathrm{~h}$ for the mixing time. The standard material composition is $6: 4$ for $\mathrm{KL} / \mathrm{TH}, 13 \%$ for $\mathrm{CR}$ content, 40 for mesh number of CR, and $2 \%$ for SBS content. Notice that the other variables remain the standard value, when one factor was changed and studied. At last part, 13\% CR and 2\% SBS modified asphalt at standard preparation procedure was made and reported as CR/SBSMA. The SBS modified asphalt with 5\% SBS content and CR modified asphalt with $13 \%$ CR content were made at standard preparation procedure, and named as SBSMA and CRMA, respectively.

\subsection{Conventional Performance Tests}

In this work, conventional performance of the modified asphalt binders concludes: penetration, softening point, ductility and storage stability. These performance tests have a superior advantage over rheology characterization tests: much lower price of the testing equipment. Penetration $\left(25^{\circ} \mathrm{C}, 100 \mathrm{~g}, 5 \mathrm{~s}\right)$, softening point $(\mathrm{R} \& \mathrm{~B})$ and ductility $\left(5 \mathrm{~cm} / \mathrm{min}, 5^{\circ} \mathrm{C}\right)$ were conducted in accordance with ASTM D5, D36 and D113, respectively. The storage stability test was carried out following the ASTM D5976. The detailed procedure of storage stability test is as follows:

The modified asphalt sample $(50 \mathrm{~g})$ was heated and poured into an aluminum tube $(25 \mathrm{~mm}$ diameter, $140 \mathrm{~mm}$ height); then the samples were vertically placed in an oven with $163^{\circ} \mathrm{C} \pm 5^{\circ} \mathrm{C}$ for $48 \mathrm{~h}$; the samples were transferred to a refrigerator until they became to the solid, after which the aluminum tube was evenly cut to three sections; last, the softening point of the top and bottom was measured and the difference (Eq. (1) was used to characterize the storage stability (according to ASTM D7173-20).

$S S=\left|P_{\text {top }}-P_{\text {bottom }}\right|$

\subsection{Rheological Properties Tests}

\subsubsection{Temperature Sweep Test}

The DSR (Anton Paar SmartPave 92) was used in all rheological tests. Before temperature sweeps, strain sweeps were first carried out to determine the linear viscoelastic range, where the complex modulus went down to $95 \%$ of its initial value [34]. The temperature sweeps were carried out from $0^{\circ} \mathrm{C}$ to $80^{\circ} \mathrm{C}$, and parallel plate geometry switched from 8 to $25 \mathrm{~mm}$ when temperature was higher than $40^{\circ} \mathrm{C}$. The complex modulus and phase angle curves were constructed by averaging the results of two replicate specimens.

\subsubsection{Multiple Stress Creep and Recovery Test}

Multiple stress creep and recovery (MSCR) could well simulate the vehicle loading on the pavements, and also non-recoverable creep compliance (Jnr) has been proved to have a higher correlating relationship with rutting performance of mixtures than rutting factor $\left(\mathrm{G}^{*} / \mathrm{sin} \delta\right)[35,36]$. MSCR of this work was conducted at $64^{\circ} \mathrm{C}$ following AASHTO T 350, with the samples that have experienced the short-term aging (RTFO). From there, Jnr and Recovery (R) at $3.2 \mathrm{kPa}$ (reported as Jnr3.2 and R3.2, respectively) was obtained to indicate high-temperature performance of the modified asphalt. 


\subsubsection{Bending Beam Rheometer Test}

Low temperature performance was characterized on the bending beam rheometer (BBR) test at various low temperatures $\left(-12^{\circ} \mathrm{C},-18^{\circ} \mathrm{C},-24^{\circ} \mathrm{C}\right.$ and $\left.-30^{\circ} \mathrm{C}\right)$, according to ASTM D6648, after the modified asphalt binders were subjected to the standard short-and long-term aging (RFTO and Pressurized Aging Vessel, PAV). Stiffness and m-value at low temperature could be obtained from BBR tests. The stiffness could indicate resistance to the constant testing load of the modified asphalt binders, but high stiffness would lead to high stress introduced by the temperature. The m-value represents the change rate of stiffness versus time, meanwhile a high m-value reveals a good ability to relax inner stress.

\section{Results and Discussions}

\subsection{Effect of Preparation Process on the Conventional Asphalt Performance}

\subsubsection{Shearing Temperature and Time}

Effect of shearing temperature and time during the preparation for CR and SBS composite modified asphalt binders on the conventional performance is reported in Fig. 3.
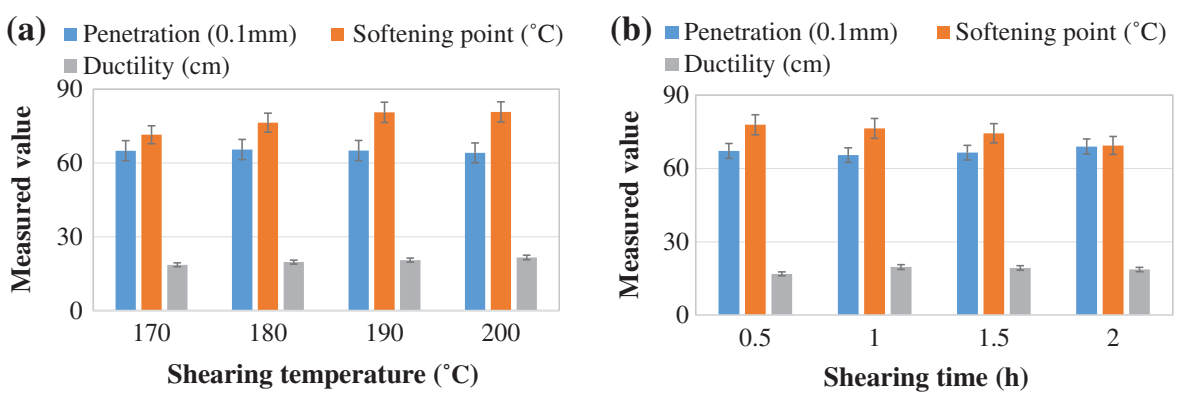

Figure 3: The effect of shearing time and temperature on the conventional performance. a): shearing time, b): shearing time

High temperature could help facilitate both swelling of CR and dispersing as well as the critical networks formation of SBS. Meanwhile, it also should be noticed that extreme high temperature may lead to extra aging on the base binders. From Fig. 3a, rising shearing temperature had a clear effect of increasing softening point of the modified binders. Also, a drop trend was observed in penetration as temperature. The increasing softening point and decreasing penetration may indicate an enhancing high-temperature performance of the modified binders when shearing temperature goes up. As for ductility, increasing temperature also had a positive effect, though the change extent was not as large as penetration and softening point. It, however, should be pointed out that the benefit on high-temperature performance was very small (softening point and penetration nearly unchanged), when temperature exceeded $190^{\circ} \mathrm{C}$.

Fig. $3 \mathrm{~b}$ depicts effect of shearing time on penetration, softening point and ductility of the modified binders. There is an optimal shearing time length for both high-and low-temperature performance, both of which reached the best when the shearing time was about $1 \mathrm{~h}$. Extra shearing time could exert the negative effect on the high-and low-temperature performance.

\subsubsection{Mixing and Swelling Time}

After shearing, the residue (containing CR, SBS and blended asphalt) experienced the mixing and swelling procedures. Effect of mixing and swelling time on the conventional performance is shown in Fig. 4.

From Fig. $4 \mathrm{a}$, it can be concluded that rising mixing temperature also benefit the high-temperature performance, with penetration decreasing and softening point increasing as mixing time. As for ductility, 
it went up before $1.5 \mathrm{~h}$ of mixing time, and then started to drop. This trend may be attributed to aging on the base binder during mixing at high temperature $\left(180^{\circ} \mathrm{C}\right)$, to some extent.

Swelling is the last procedure of preparation, where the residue was conditioning at oven $\left(180^{\circ} \mathrm{C}\right)$ for the certain length of time. From Fig. 4b, it can be found that the suitable swelling time length would benefit both low-and high-temperature. Ductility, penetration and softening reached the optimum at $1 \mathrm{~h}$ of swelling time.
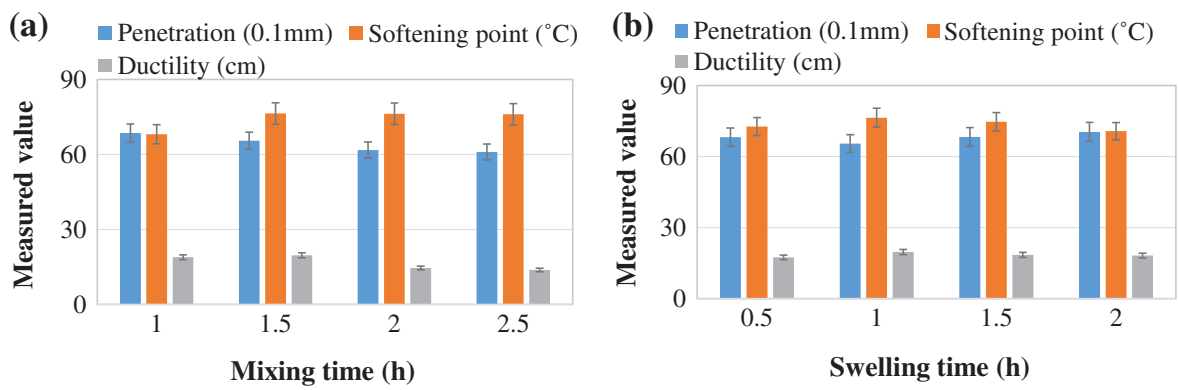

Figure 4: The effect of mixing time and temperature on the conventional performance. a): mixing time, b): swelling time

\subsection{Effect of Material Composition on the Conventional Asphalt Performance}

\subsubsection{Mass Ratio of KL and TH}

Many researches have proved and confirmed that the difference of chemical composition in asphalt binder could results in a distinct variation on the performance of the modified asphalt $[1,3]$. The results of influence of mass ratio between $\mathrm{KL}$ and $\mathrm{TH}$ on the conventional performance is shown in Fig. 5.

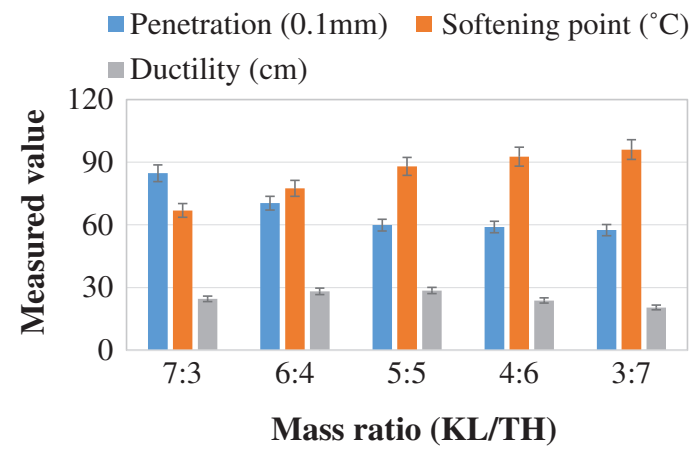

Figure 5: The effect of mass ratio of $\mathrm{KL}$ and $\mathrm{TH}$ on the conventional performance

From the trend of penetration and softening point, it is clear that higher content of TH in the blended asphalt could benefit the high-temperature performance for the modified asphalt, meanwhile the changing rate of penetration and softening point slowed down, when the content of $\mathrm{TH}$ reached $60 \%$. As for ductility, it first went up and then decreased as the content of TH increased. The ductility reached the peak when mass ratio was 5:5. It also should be noticed that ductility at mass ratio of 6:4 is very close the peak value, but $60 \% \mathrm{KL}$ means high KL asphalt binder could be used, which is encouraged by this project. 


\subsubsection{CR Content and Mesh Number}

Fig. 6 presents the effect of CR content and particle size (mesh number) on the conventional performance. A consistent trend was witnessed on penetration and softening point, as CR content increased from $11 \%$ to $19 \%$, in Fig. 6a. It was observed that the penetration dropped and the softening point rose as CR content went up. Yet, higher CR content might not necessarily lead to a higher ductility, since ductility reached the highest value at $13 \%$ of CR content. This may be explained the light fractions (aromatic and saturation) absorption by CR particles. More CR particles could result in higher absorption of light fractions, which may exert a negative effect on the colloidal structure of base binder and ductility.
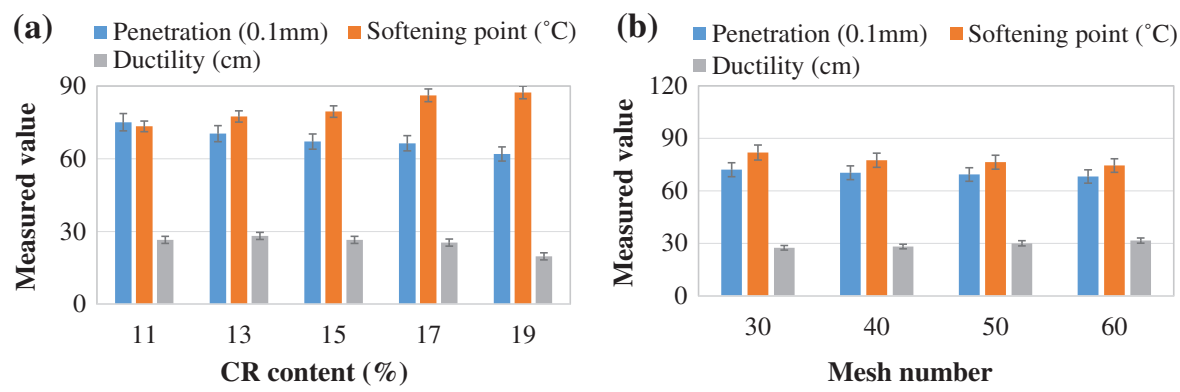

Figure 6: The effect of CR content and mesh number on the conventional performance. a): CR content, b): mesh number

From Fig. 6b, the particle size of CR also influences conventional performance of the modified asphalt. It can be known that reducing the CR particle size (higher mesh number) could slightly improve ductility, while it would cause some negative effects on penetration and softening point, from perspective of antirutting property.

\subsubsection{SBS Content}

SBS polymers have an obvious effect of enhancing high-temperature for asphalt binders. It can be confirmed by Fig. 7, where penetration kept decreasing and softening point kept increasing as SBS content went up. On the other hand, it has not been observed a great change on ductility, with ductility remaining the level of about $30 \mathrm{~cm}$, when SBS content increased from $1.5 \%$ to $3.5 \%$.

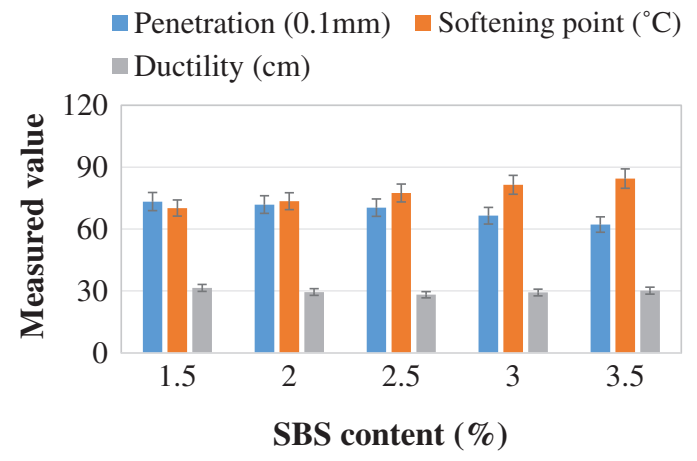

Figure 7: The effect of SBS content on the conventional performance

\subsubsection{Storage Stability}

Due to the differences of solubility and density among the base binder (blended asphalt) and CR as well as SBS, CR and SBS particles tend to accumulate and float at top of the modified asphalt during the storage process. 
It can be inferred from Fig. 8a that the base binder (blended asphalt) would influence the storage stability of CR and SBS composite modified asphalt. The high ratio of KL asphalt binder in blended asphalt (70\% and $60 \%$ ) contributed to a relatively high softening point difference (bad storage stability). But the storage ability remained stable when the ratio of KL was equal or smaller than $50 \%$.

(a)

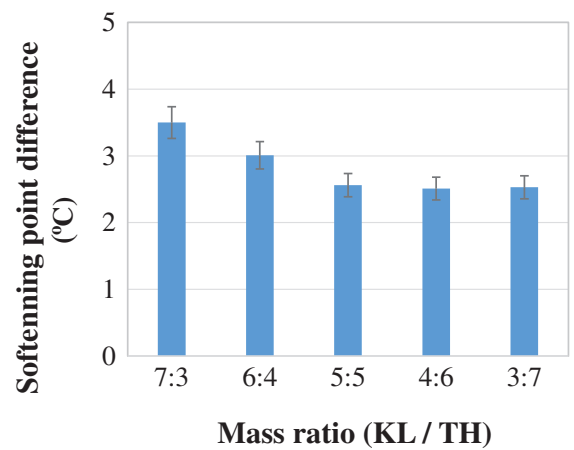

(c)

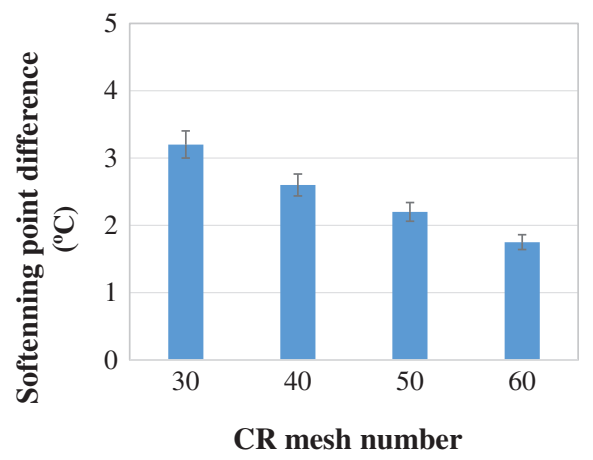

(b)

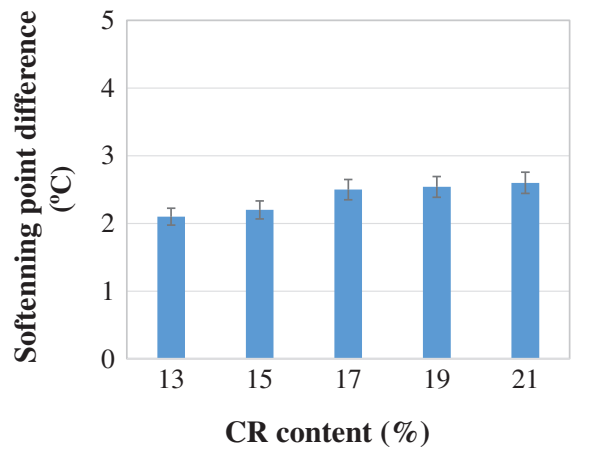

(d)

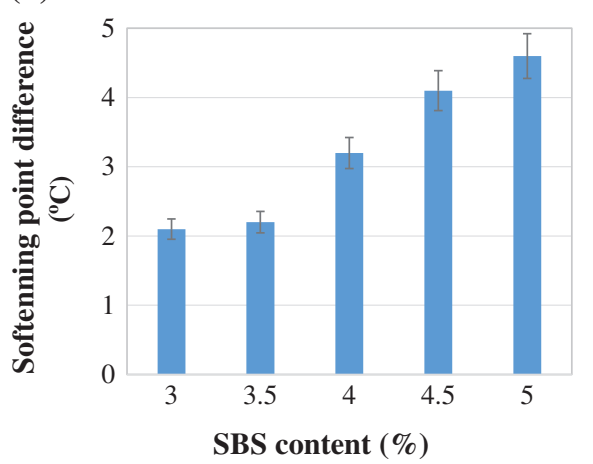

Figure 8: The effect of material composition on the storage stability. a): mass ratio of KL/TH, b): CR content, c): mesh number of CR, and d): SBS content

Figs. $8 \mathrm{~b}$ and $8 \mathrm{c}$ prove that $\mathrm{CR}$ content and particle size can also play a role in determining storage ability of the modified asphalt. The softening point difference kept increasing when CR content was less than 17\%, and it became relatively stable when CR content was more than $17 \%$. Lowering the size of CR particle could improve storage stability of modified asphalt (the softening point difference going down). It may be attributed to the more sufficient swelling, when CR size is smaller. It can be known from Fig. 8d, the softening point difference went up as the SBS content increased. This is because high SBS polymers in binders lead to phase separation of the modified asphalt [3].

\subsection{Rheological Performance of CR/SBS Composite Modified Asphalt}

To better understand and prove the superior performance of CR and SBS modified asphalt, the CR/ SBSMA sample, prepared by the selected preparation process and material composition, was investigated in terms of rheological performance, and subsequently was compared with other samples, including SBSMA, CRMA and blended asphalt (base binder).

\subsubsection{Temperature Sweeps}

Complex modulus at temperature range of $0^{\circ} \mathrm{C}-80^{\circ} \mathrm{C}$ is presented in Fig. 9a. Clearly, it can be seen that the curve of CR/SBSMA remained at the highest position of the figure during the whole temperature range, 
revealing that the combination of CR and SBS performed a better effect of enhancing complex modulus than other samples. At the high temperature region $\left(40^{\circ} \mathrm{C}-80^{\circ} \mathrm{C}\right)$, the gap of complex modulus among samples is more obvious than it of the low temperature region $\left(0^{\circ} \mathrm{C}-40^{\circ} \mathrm{C}\right)$. Meanwhile, it should be noticed that the rutting phenomenon at asphalt pavement normally occurs at the high temperature. So, CR/SBSMA could perform obviously better than other samples in anti-rutting, from the perspective of complex modulus.
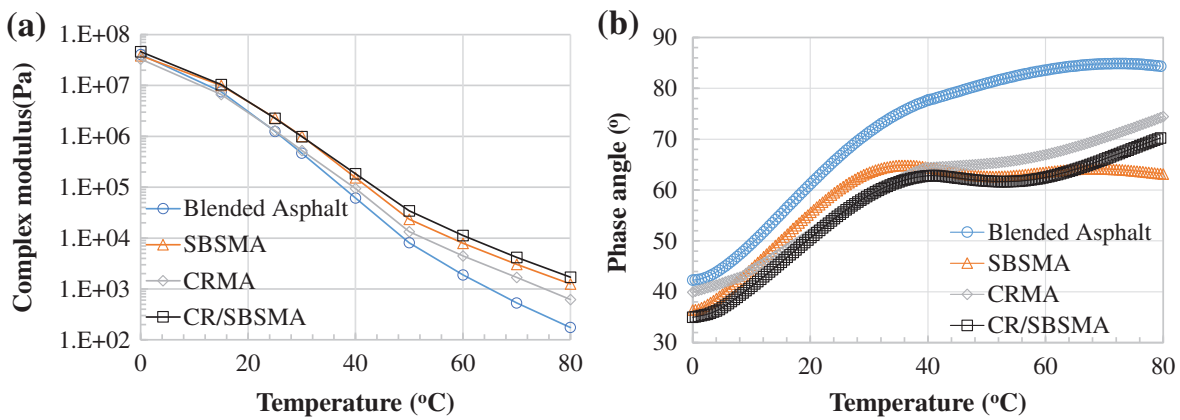

Figure 9: Complex modulus and phase angle results from temperature sweeps from $0^{\circ} \mathrm{C}$ to $80^{\circ} \mathrm{C}$. a): complex modulus, b): phase angle

Fig. 9b depicts the phase angle results. Phase angle has long been used to characterize viscoelasticity of asphalt materials, meanwhile a higher phase angle normally represents a stronger vicious response of the material. At low temperature zone $\left(<40^{\circ} \mathrm{C}\right)$, a similar trend was witnessed at the curves for all samples. Phase angle increased with temperature, indicating a rising elastic response. Yet, the situation could be different at high temperature region $\left(>80^{\circ} \mathrm{C}\right)$. There is not an identical trend for phase angle curves for all samples.

The typical shape of phase angle curve for SBSMA was observed. This curve remained nearly unchanged at high temperature region, which is attributed by the formation of 3D SBS networks and physical crossing-linking among polystyrene blocks. This flat-curve shape could also be seen at CR/SBSMA. It should be noticed that the flat part of the phase angle curve for CR/SBSMA is smaller than it of SBSMA, since the lower SBS content ( $2 \%$ and 5\%). As for CRMA and blended asphalt, their phase angle increased as temperature at whole temperature range. As a conclusion, SBSMA and CR/SBSMA performed a stronger elastic response than other two samples, since the lower phase angle.

\subsubsection{MSCR}

Researches has been proved that Jnr obtained from MSCR share a stronger correlating relationship with anti-rutting performance at high temperature, as compared with the rutting factor [35,36]. R3.2 and Jnr3.2 at $64^{\circ} \mathrm{C}$ are shown in Fig. 10.

Notice that R3.2 of blended asphalt is 0 , which means that the neat binder, containing no modifier, have no capability to recover any strain at the rest period of MSCR at $64^{\circ} \mathrm{C}$. All strains under the load of MSCR tests would accumulate and form the permanent deformation. R3.2 experienced a significant increase after adding modifiers, with the figure reaching 45\% (CRMA) and even about 80\% (SBSMA and CR/ SBSMA). The addition of CR and SBS greatly improved the ability of binders to recover the strain at MSCR.

According to Jnr3.2, AASHTO MP 19 further categorize high-temperature rutting performance into four levels: "E", "V" "H" and "S", corresponding to extreme high, very high, high and standard loading, respectively. A lower Jnr3.2 means a better rutting performance. A similar consequence as R3.2 has been seen in Jnr3.2. After the CR and/or SBS addition, Jnr3.2 greatly went down. CR/SBSMA and SBSMA reached the highest level, E, with Jnr3.2 greatly lower than 0.5 (the limit of E level). Though, compared 
with the blended asphalt, anti-rutting performance of CRMA has been greatly improved, with Jnr3.2 equal to 0.68 , but there is an obvious gap among CRMA and SBSMA as well as CR/SBSMA. The rank follows as: CR/SBSMA $>$ SBSMA $>$ CRMA $>$ blended asphalt.

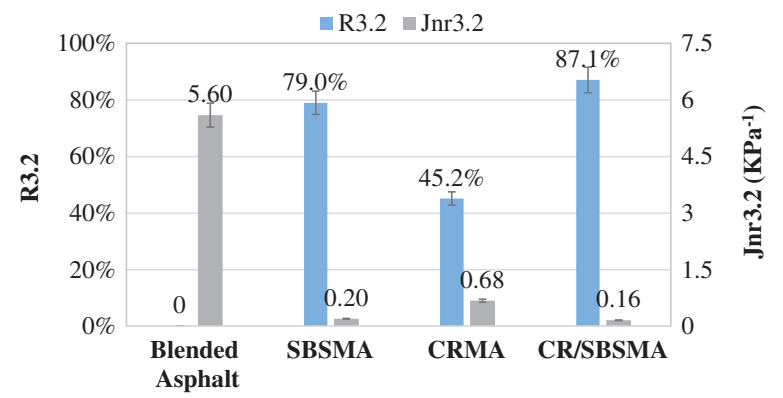

Figure 10: R3.2 and Jnr3.2 and obtained from MSCR tests at $64^{\circ} \mathrm{C}$

\subsubsection{BBR}

Cracking performance of asphalt binders at low temperature are governed by both creep stiffness and the ability to relax the accumulated inner stress (m-value). In general, the stress introduced by temperature could be very quick to build up at the stiff asphalt binders. So, it requires the enough ability to relax the inner stress, and otherwise cracking would occur and accumulate on the asphalt binders.

It can be seen from Fig. 11a that the stiffness of all samples obviously went up as temperature decreased. Yet, the increasing rate of stiffness of each sample varied. For example, the stiffness of blended asphalt is lower than it of the modified asphalt binders at $-12^{\circ} \mathrm{C}$, while it became larger than others at $-24^{\circ} \mathrm{C}$ and $-18^{\circ} \mathrm{C}$. From the stiffness, all samples exhibited an acceptable low-temperature performance at $-18^{\circ} \mathrm{C}$, with the figures remaining under $300 \mathrm{MPa}$.
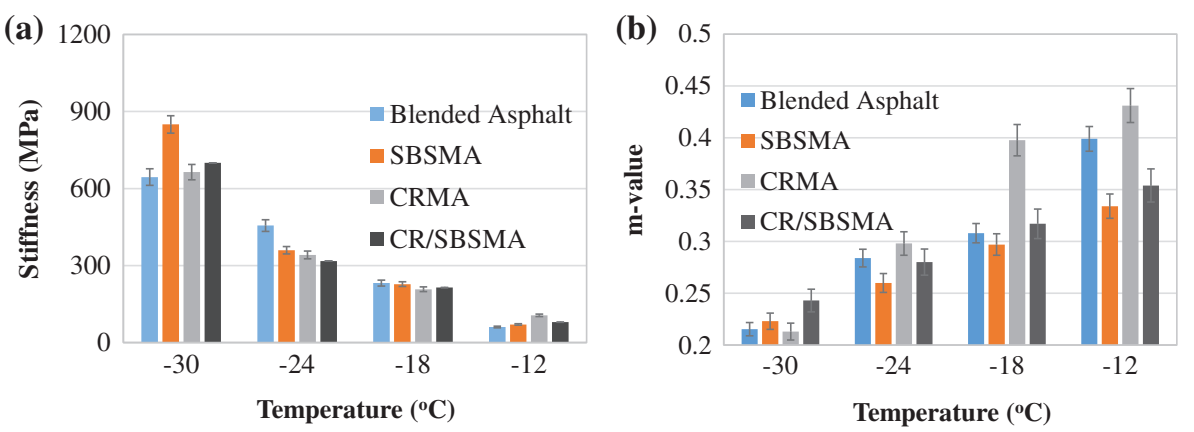

Figure 11: Stiffness and $\mathrm{m}$-value results from BBR at various temperatures. a): stiffness, b): $\mathrm{m}$-value

From Fig. 11b, decreasing temperature can be seen have an effect of reducing m-value of all samples, and at the same time, the reducing rate of m-value for each sample varied. Also, it can be known that m-value of CRMA went down at a quicker rate than others, while adding SBS into CRMA (CR/SBSMA) had an effect of slowing down the decreasing rate.

Low-temperature cracking performance in this work was evaluated by continuous low-temperature PG, which was calculated by linearly interpolating stiffness and $\mathrm{m}$-value at various temperatures, following the criterion of stiffness no more than $300 \mathrm{MPa}$ and m-value larger than 0.3 . 
From Fig. 12, the low-temperature performance grade (PG) determined by stiffness went up greatly, if only SBS modifiers added. It proves that SBS has an obvious effect of increasing stiffness at low temperature, which makes it prone to cracking. Notice that combining CR and SBS helped control the increase of the low-temperature PG, with the PG of CR/SBSMA remaining the same level as blended asphalt. Of course, CRMA has the lowest PG for stiffness grade.

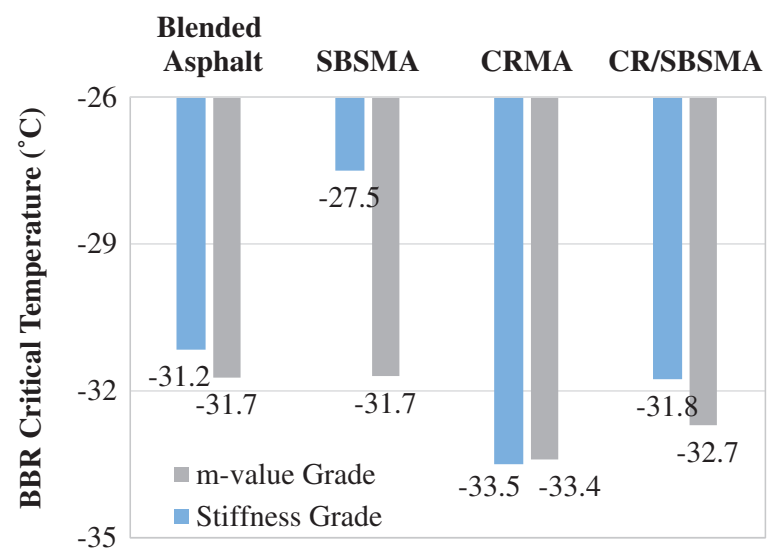

Figure 12: Continuous low-temperature PG results of each sample

On the other hand, the addition of SBS did not exert much negative effect on m-value. Before and after adding SBS, the PG determined by $\mathrm{m}$-value remained stable (-31.7). Meanwhile, it also can be seen that the addition of CR helped improve the ability to relax the inner stress of asphalt binders, with the PG of CRMA reaching the peak (-33.4). CR/SBSMA also performed better than blended asphalt in terms of the PG of mvalue. In a conclusion, even the addition of SBS would impair the low-temperature due to its hardening effect, while the incorporation of CR would relieve it. So, the low-temperature of CR/SBSMA could reach the level of the neat binder (blended asphalt).

\section{Conclusions}

From the economic and environmental purpose, CR could be used as an addictive in paving asphalt binders. This study also proves that incorporating CR and SBS to modify local-produced asphalt binders, at a suitable preparing condition and material composition, could be a promising technology, because a good high-and low-temperature performance could be successfully obtained at the same time. Some factors in preparing process and material composition have been considered to find out their effects on the performance. The main conclusions from this work are as follows:

(1) Conventional performance results prove that a higher temperature and time during preparation process could lead to a better high-temperature performance, except shearing time. But rising temperature and time would necessarily exert an adverse effect on the low-temperature performance. So, the suitable temperature and time during preparation should be determined by considering both high-and low-temperature performance.

(2) The high-temperature performance keeps enhancing, as mass ratio of KL and TH, CR content and CR particle size as well as SBS content increase. As for low-temperature performance, it reaches the peak when mass ratio of $\mathrm{KL}$ and $\mathrm{TH}$ as well as CR content a is about 5:5\% and 15\%. Meanwhile reducing SBS content and CR particle size could benefit the low-temperature performance. 
(3) The softening point difference results show that increasing the content of SBS and CR could have a negative effect on the storage stability of CR and SBS modified asphalt. But reducing CR particle size and increasing TH content in base binder have an effect of improving storage stability.

(4) Temperature sweep and MSCR results confirm that combining 13\% CR and $\%$ SBS (CR/SBSMA) could obtain a superior high-temperature performance than it of SBSMA (5\% SBS). BBR results show that as compared with SBSMA, the low-temperature performance of CR/SBSMA is obviously improved. The gap between low-temperature performance of CR/SBSMA and CRMA is greatly narrowed, which could be mostly attributed to the addition of CR.

Funding Statement: This study is jointly found by the Natural Science Foundation of Jiangxi Province of China (20202BABL214046), the Natural Science Foundation of Xinjiang Uygur Autonomous Region (2020D01A92), the China Postdoctoral Foundation (2020M683709XB), and the Research Project of China Railway City Development \& Investment Group Co. Ltd.

Conflicts of Interest: The authors declare that they have no conflicts of interest to report regarding the present study.

\section{References}

1. Lesueur, D. (2009). The colloidal structure of bitumen: Consequences on the rheology and on the mechanisms of bitumen modification. Advances in Colloid and Interface Science, 145(1-2), 42-82. DOI 10.1016/j. cis.2008.08.011.

2. Yildirim, Y. (2007). Polymer modified asphalt binders. Construction and Building Materials, 21(1), 66-72. DOI 10.1016/j.conbuildmat.2005.07.007.

3. Zhu, J., Birgisson, B., Kringos, N. (2014). Polymer modification of bitumen: Advances and challenges. European Polymer Journal, 54(5), 18-38. DOI 10.1016/j.eurpolymj.2014.02.005.

4. Xu, J., Pei, J., Cai, J., Liu, T., Wen, Y. (2021). Performance improvement and aging property of oil/SBS modified asphalt. Construction and Building Materials, 300(5), 123735. DOI 10.1016/j.conbuildmat.2021.123735.

5. Airey, G. D. (2003). Rheological properties of styrene butadiene styrene polymer modified road bitumens. Fuel, 82(14), 9-19. DOI 10.1016/S0016-2361(03)00146-7.

6. Kim, T. W., Baek, J., Lee, H. J., Choi, J. Y. (2013). Fatigue performance evaluation of SBS modified mastic asphalt mixtures. Construction and Building Materials, 48(Complete), 908-916. DOI 10.1016/j.conbuildmat.2013.07.100.

7. Li, N., Xu, J., Xu, T. (2021). Preparation, properties and modification mechanism of vulcanized eucommia ulmoides gum modified asphalt. Construction and Building Materials, 274, 121992. DOI 10.1016/j. conbuildmat.2020.121992.

8. Yao, X., Wang, Y., Xu, T. (2021). Development on recycling, aging simulation and regeneration methods of reclaimed styrene-butadiene-styrene modified asphalt. Journal of Cleaner Production, 312, 127767. DOI 10.1016/j.jclepro.2021.127767.

9. Khodaii, A., Mehrara, A. (2009). Evaluation of permanent deformation of unmodified and SBS modified asphalt mixtures using dynamic creep test. Construction and Building Materials, 23(7), 2586-2592. DOI 10.1016/j. conbuildmat.2009.02.015.

10. Chen, J., Huang, C. (2010). Fundamental characterization of SBS-modified asphalt mixed with sulfur. Journal of Applied Polymer, 103(5), 2817-2825. DOI 10.1002/(ISSN)1097-4628.

11. Zanzotto, L., Stastna, J., Vacin, O. (2000). Thermomechanical properties of several polymer modified asphalts. Applied Rheology, 10(4), 185-191. DOI 10.1515/arh-2000-0012.

12. Ming, L., Peng, L., Fan, W., Qian, C., Nan, G. (2005). Thermo-rheological behavior and compatibility of modified asphalt with various styrene-butadiene structures in SBS copolymers. Materials and Design, 88, 177-185. DOI 10.1016/j.matdes.2015.09.002. 
13. Masson, J. F., Collins, P., Robertson, G., Woods, J. R., Margeson, J. (2003). Thermodynamics, phase diagrams, and stability of bitumen-polymer blends. Energy and Fuels, 17(3), 714-724. DOI 10.1021/ef0202687.

14. Hernandez, G., Medina, E. M., Sanchez, R., Mendoza, A. M. (2006). Thermomechanical and rheological asphalt modification using styreneButadiene triblock copolymers with different microstructure. Energy and Fuels, 20(6), 2623-2626. DOI 10.1021/ef050393t.

15. Airey, G. D. (2002). Rheological evaluation of ethylene vinyl acetate polymer modified bitumens. Construction and Building Materials, 16(8), 473-487. DOI 10.1016/S0950-0618(02)00103-4.

16. Xu, J., Sun, L., Pei, J., Xue, B., Li, R. (2020). Microstructural, chemical and rheological evaluation on oxidative aging effect of SBS polymer modified asphalt. Construction and Building Materials, 267, 121028. DOI 10.1016/j. conbuildmat.2020.121028.

17. Yan, C., Huang, W., Lin, P., Zhang, Y., Lv, Q. (2019). Chemical and rheological evaluation of aging properties of high content SBS polymer modified asphalt. Fuel, 252, 417-426. DOI 10.1016/j.fuel.2019.04.022.

18. Zhang, J., Huang, W., Zhang, Y., Yan, C., Guan, W. (2021). Evaluation of the terminal blend crumb rubber/ SBS composite modified asphalt. Construction and Building Materials, 278(2), 122377. DOI 10.1016/ j. conbuildmat.2021.122377.

19. Diekmann, A., Giese, U., Schaumann, I. (2019). Polycyclic aromatic hydrocarbons in consumer goods made from recycled rubber material: A review. Chemosphere, 220, 1163-1178. DOI 10.1016/j.chemosphere.2018.12.111.

20. Bansal, S., Misra, A. K., Bajpai, P. (2017). Evaluation of modified bituminous concrete mix developed using rubber and plastic waste materials. International Journal of Sustainable Built Environment, 6(2), 442-448. DOI 10.1016/j.ijsbe.2017.07.009.

21. Nejad, F. M., Aghajani, P., Modarres, A., Firoozifar, H. (2012). Investigating the properties of crumb rubber modified bitumen using classic and SHRP testing methods. Construction and Building Materials, 26(1), 481489. DOI 10.1016/j.conbuildmat.2011.06.048.

22. Cong, P., Xun, P., Xing, M., Chen, S. (2013). Investigation of asphalt binder containing various crumb rubbers and asphalts. Construction and Building Materials, 40, 632-641. DOI 10.1016/j.conbuildmat.2012.11.063.

23. Chen, T., Ma, T., Huang, X., Guan, Y., Zhang, Z. et al. (2019). The performance of hot-recycling asphalt binder containing crumb rubber modified asphalt based on physiochemical and rheological measurements. Construction and Building Materials, 226, 83-93. DOI 10.1016/j.conbuildmat.2019.07.253.

24. Li, B., Huang, W., Tang, N., Hu, J., Ling, P. et al. (2017). Evolution of components distribution and its effect on low temperature properties of terminal blend rubberized asphalt binder. Construction and Building Materials, 136, 598-608. DOI 10.1016/j.conbuildmat.2017.01.118.

25. Han, L., Zheng, M., Wang, C. (2016). Current status and development of terminal blend tyre rubber modified asphalt. Construction and Building Materials, 128, 399-409. DOI 10.1016/j.conbuildmat.2016.10.080.

26. Ming, L., Xue, X., Fan, W., Hui, L., Wang, X. et al. (2015). Investigation of the rheological properties and storage stability of CR/SBS modified asphalt. Construction and Building Materials, 74, 235-240. DOI 10.1016/j. conbuildmat.2014.10.022.

27. Fu, Q., Xu, G., Chen, X., Zhou, J., Sun, F. (2019). Rheological properties of SBS/CR-C composite modified asphalt binders in different aging conditions. Construction and Building Materials, 215, 1-8. DOI 10.1016/j. conbuildmat.2019.04.076.

28. Duan, S., Muhammad, Y., Li, J., Maria, S., Yang, H. (2019). Enhancing effect of microalgae biodiesel incorporation on the performance of crumb rubber/SBS modified asphalt. Journal of Cleaner Production, 237, 117725. DOI 10.1016/j.jclepro.2019.117725.

29. Zhang, H. L., Su, M. M., Zhao, S. F., Zhang, Y. P., Zhang, Z. P. (2016). High and low temperature properties of nano-particles/polymer modified asphalt. Construction and Building Materials, 114, 323-332. DOI 10.1016/j. conbuildmat.2016.03.118.

30. Ren, S., Liu, X., Xu, J., Lin, P. (2021). Investigating the role of swelling-degradation degree of crumb rubber on CR/SBS modified porous asphalt binder and mixture. Construction and Building Materials, 300, 124048. DOI 10.1016/j.conbuildmat.2021.124048. 
31. Ren, S., Liu, X., Li, M., Fan, W., Erkens, S. (2020). Experimental characterization of viscoelastic behaviors, microstructure and thermal stability of CR/SBS modified asphalt with TOR. Construction and Building Materials, 261, 120524. DOI 10.1016/j.conbuildmat.2020.120524.

32. Ren, S., Liu, X., Fan, W., Wang, H., Erkens, S. (2019). Rheological properties, compatibility, and storage stability of SBS latex-modified asphalt. Materials, 12(22), 3683. DOI 10.3390/ma12223683.

33. Yu, X., Burnham, N. A., Tao, M. (2015). Surface microstructure of bitumen characterized by atomic force microscopy. Advances in Colloid and Interface Science, 218, 17-33. DOI 10.1016/j.cis.2015.01.003.

34. Liang, M., Xin, X., Fan, W., Sun, H., Yao, Y. et al. (2015). Viscous properties, storage stability and their relationships with microstructure of tire scrap rubber modified asphalt. Construction and Building Materials, 74, 124-131. DOI 10.1016/j.conbuildmat.2014.10.015.

35. Huang, W., Tang, N. (2015). Characterizing SBS modified asphalt with sulfur using multiple stress creep recovery test. Construction and Building Materials, 93, 514-521. DOI 10.1016/j.conbuildmat.2015.06.041.

36. Behnood, A., Olek, J. (2017). Rheological properties of asphalt binders modified with styrenebutadiene-styrene (SBS), ground tire rubber (GTR), or polyphosphoric acid (PPA). Construction and Building Materials, 151, 464-478. DOI 10.1016/j.conbuildmat.2017.06.115. 